\title{
Studies in Growth. IV. Correlations in Development.
}

\author{
BY \\ W. H. PEARSALL. \\ With six Figures in the Text.
}

THE earlier papers of this series $(1,2)$ dealt with certain aspects of the 1 growth of yeast and of roots upon cuttings. As a result of the conclusions drawn from those special cases, it appeared to be possible to

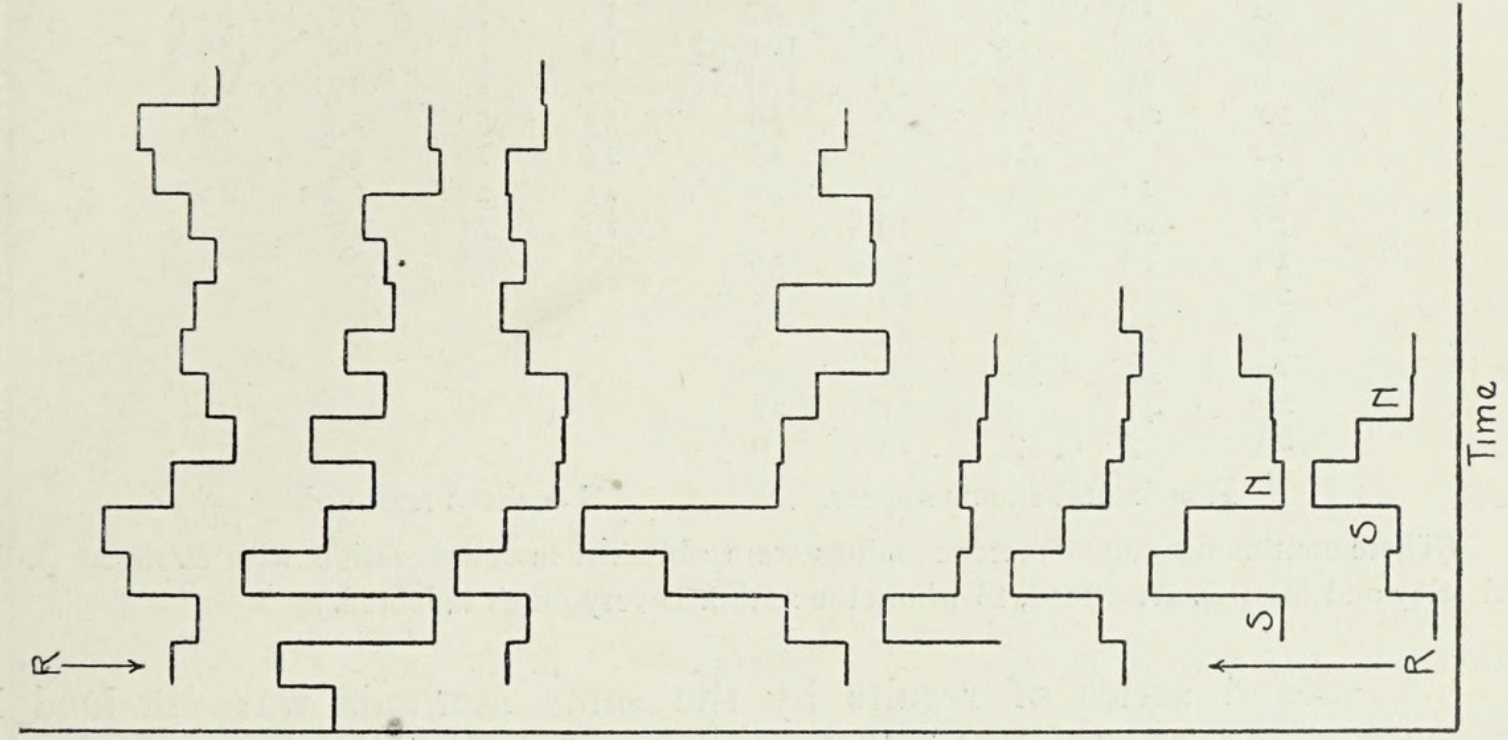

Volume increase (. Olcc per 2 days)

FIG. I. Rate of growth of bean roots in volume. $R$ indicates appearance of secondary roots; stem removed at $\mathrm{S}$; new shoots appear at $\mathrm{N}$.

explain some of the earlier data obtained in these studies, which had until recently seemed to be of little value.

The first measurements undertaken in this connexion were those of the volumes of roots grown from Broad Beans (Vicia Faba, L.), the root volumes being measured in a volumometer as previously described (8). In the first series of observations, begun on July $3^{\mathrm{I}}, \mathrm{I} 92 \mathrm{2O}$, the beans were grown in Shive's optimum three-salt culture solution (9), this being renewed every two days. The volumometers were kept in a water-bath, at an approximately constant temperature of $I 5^{\circ} \mathrm{C} .\left( \pm \mathrm{I}^{\circ}\right)$. The water-bath was covered so that the roots were in the dark. The whole apparatus was set up in an artificially warmed greenhouse.

[Annals of Botany, Vo1. XXXVII. No. CXLVI. April, 1923.] 
The results of the measurements upon these beans are given in Table I (Fig. I) as rates of growth (i.e. increase in volume per two days). There are insufficient data for the analysis of these curves, but they show the characteristic depression of the rate of growth following (in the case of volume measurements) the appearance of secondary roots. The rate of root growth then increases once again, when a second factor causes a second drop in the growth rate, which subsequently becomes roughly constant. The appearance of tertiary roots was not responsible for this second depression of the growth rate and consequently some other factor is involved.

\section{TABLE I.}

Volume Increase of Bean Roots (in $\frac{1}{100}$ c.c. per two days).

\begin{tabular}{ccccc}
\multicolumn{5}{c}{ Series $I$ (August). } \\
Days & I & 2 & 3 & 4 \\
2 & $29 \mathrm{R}$ & $5 \mathrm{I}$ & $30 \mathrm{R}$ & $\mathrm{I} 8 \mathrm{R}$ \\
4 & $\mathrm{I} 6$ & $74 \mathrm{R}$ & $\mathrm{I} 8$ & 47 \\
6 & 48 & 5 & 50 & $\mathrm{IO1}$ \\
8 & 59 & $9 \mathrm{I}$ & $3 \mathrm{I}$ & $\mathrm{I} 38$ \\
$\mathrm{I0}$ & 29 & 54 & 6 & 59 \\
$\mathrm{I} 2$ & 0 & 33 & 3 & 57 \\
$\mathrm{I} 4$ & $\mathrm{I} 2$ & $6 \mathrm{I}$ & 0 & $4 \mathrm{I}$ \\
$\mathrm{I} 6$ & 24 & 27 & $\mathrm{I} 9$ & 8 \\
$\mathrm{I} 8$ & $\mathrm{I} 8$ & 46 & 30 & 58 \\
20 & 9 & 23 & 20 & $\mathrm{I} 4$ \\
22 & 20 & 27 & 36 & $\mathrm{I} 6$ \\
24 & 37 & 38 & 38 & 40 \\
26 & 44 & 2 & $\mathrm{II}$ & 27 \\
28 & 7 & 7 & $\mathrm{I} 3$ & 0 \\
\multicolumn{4}{c}{$\mathrm{R}=$ lateral shoots appear. }
\end{tabular}

\begin{tabular}{cccc}
\multicolumn{4}{c}{ Series II (September). } \\
5 & 6 & 7 & 8 \\
$\mathrm{R}$ & $27 \mathrm{R}$ & $\mathrm{I} 8 \mathrm{~S}$ & 10 \\
70 & 37 & 77 & 32 \\
34 & 78 & 62 & $26 \mathrm{~S}$ \\
30 & 55 & 17 & 64 \\
35 & 36 & 23 & 45 \\
24 & 29 & 23 & $2 \mathrm{I}$ \\
$2 \mathrm{I}$ & 28 & 38 & 20 \\
$\mathrm{I} 9$ & $2 \mathrm{I}$ & 20 & \\
& 30 & & \\
& & & \\
$\mathrm{~S}=$ shoot removed.
\end{tabular}

(These continuous volumometer readings were obtained in collaboration with Professor $\mathrm{J}$. H. Priestley and Miss D. Armstead, to whom the author is very much indebted.)

A second series of results by the same methods was obtained in September, I920. More detailed notes on the whole plants are available, and it is possible to recognize the distinctive features of the rate curve more clearly and to correlate them with other growth factors. The results are also embodied in Fig. I.

The first measurements were taken at the time of the appearance of the secondary roots, except in the case of No. 5, where the roots developed rather earlier. The growth rate, at first therefore low, rose rapidly, and then in all cases again fell to a low level as in the previous series. The second drop in root growth was very definitely associated with the rapid development of the stem, which grew rapidly after the appearance of secondary roots, so that the depression of the root growth rate corresponded with the maximum production of stem and leaves. The demands of such a developing shoot on food supply from the cotyledons must be equal to or greater than those of the roots, and the rapid development of the shoot seems to imply, therefore, a diversion of the food supply from the 
root apices and a consequent limitation of their rate of growth. If the stem for any reason stopped growing, we should expect the roots to grow at an increased rate.

In Nos. 7 and 8 of this series the shoot was removed, and a marked increase in the rate of growth for the next four days was the result of this operation. The rate of root growth then fell again to a low rate, and about the fifth or sixth day new shoots were visible, the falling off in root growth apparently being due to their development.

These assumptions were examined further by growing peas (Pisum sativum) and determining the average weight of stems and of roots at fixed intervals. In order to avoid complications due to photosynthetic effects on dry weight the peas were grown in the dark. This does not appear to alter materially either the rate or the total amount of root growth. Attempts were also made to eliminate some of the extreme variability observed in some earlier experiments. Two main types of variation were usually observed: (I) variability in germination, presumably due to variations in the thickness and permeability of the seed-coat; (2) variability in subsequent development. To get a moderately uniform and fairly representative set of growing peas, about three thousand peas were spread out and soaked in sufficient Shive's optimum three-salt solution to just cover them. On germination about three hundred of these were selected, having roots of average and similar length $(\mathrm{I} \cdot 5-2 \cdot 5 \mathrm{~cm}$.), the extreme variants being thus eliminated. The selected plants were then grown with their roots dipping through a perforated plate into the Shive's solution. The cotyledons rested upon filter-paper and the seeds were kept in incubators at fairly constant temperature and humidity. The nutrient solution was changed every three days.

In Series III no further elimination of variations was made, but in Series IV to VI no determinations were made until the appearance of secondary roots-and then the material was graded according to the length of the shoots, equal numbers of plants with very long or very short shoots being discarded. In this way only about Ioo to I 50 plants were left, the extreme variants having been eliminated at two stages in the growth-cycle on two criteria, (I) root length, (2) stem length.

The samples for determination of the dry weight were taken in lots of ten. The attachment to the cotyledon was treated as part of the rootsince it increases in weight in proportion to the root-and after cutting the plant away from the cotyledons at the junction of the attachments and cotyledons, the stem was also cut off just above the attachment. The roots, stems, and cotyledons were then dried for six hours at $100^{\circ} \mathrm{C}$. and parts of each plant weighed separately. The average dry weight and probable error of the set of ten plants were then determined.

A modification in the method of sampling was introduced in the case of Series III, IV, and VI. In these series, equal numbers of the extreme 
variants were selected for each determination, the criterion being stem length. In this way, the plants remaining for the later determinations approximated more and more closely to the average of the material; the later determinations are probably more reliable, and their probable error is smaller. The probable error was not determined for the earlier readings (stem weight) in Series IV, V, and VI, since the individual weights are too small to measure accurately.

\section{RESULTS.}

Series III was carried out at a temperature of $25^{\circ} \mathrm{C} .\left( \pm 0.5^{\circ}\right)$. In this an effort was made to obtain the complete growth curve and the results are recorded in Table II (Fig. 2). The figures for root growth show the characteristic stoppage of root growth previously recorded for roots on Tradescantia cuttings and for Broad Bean roots (volume measurements). The roots finally ceased growing about the ninth day, and no tertiary roots appeared either at this time or later (such as were found in Tradescantia). The stem at the ninth day, however, was growing at the maximum rate, and it was still growing at the conclusion of the observations. No marked increase in stem weight took place until the appearance of secondary roots, after which the elongation of the stem was very noticeable.

\section{TABLE II.}

Average Dry Weight of Peas (green wrinkled variety).

\begin{tabular}{|c|c|c|}
\hline \multicolumn{3}{|c|}{ Series III $\left(25^{\circ}+\mathrm{I}^{\circ} \mathrm{C}.\right)$. } \\
\hline Day. & Shoot. & Root. \\
\hline I & I.O mg. & 2. I mg. \\
\hline $\mathrm{I} \cdot 5$ & $1 \cdot 3$ & 2.8 \\
\hline 2 & $I \cdot 4$ & $4.8 \pm 0$. I I \\
\hline $2 \cdot 5$ & $I \cdot 9$ & $6.0 \pm 0.20$ \\
\hline 3 & $3 \cdot 0$ & $7 \cdot 4 \pm 0.29$ \\
\hline $3 \cdot 5$ & $3.5 \pm 0.04$ & $8 \cdot 7 \pm 0.40$ \\
\hline 4 & $3.5 \pm 0.07$ & $11 \cdot 2 \pm 0.3^{2}$ \\
\hline $4 \cdot 5$ & $5 \cdot 7 \pm 0.30$ & I $2.2 \pm 0.7 \mathrm{I}$ \\
\hline 5 & $6.2 \pm 0.30$ & I $2 \cdot 4 \pm 0.47$ \\
\hline $5 \cdot 5$ & $7.6 \pm 0.35$ & $13 \cdot \mathrm{I} \pm \mathrm{I} \cdot \mathrm{O}$ \\
\hline $6 \cdot 5$ & I $2 \cdot 7 \pm I .0$ & $16 \cdot I \pm I \cdot I$ \\
\hline $7 \cdot 5$ & $18 \cdot 4 \pm I \cdot 2$ & $20 \cdot 4 \pm \mathrm{J} \cdot 8$ \\
\hline $8 \cdot 5$ & $30.0 \pm 2.4$ & $28 \cdot 3 \pm 1.8$ \\
\hline $9 \cdot 5$ & $4^{I} \cdot 8 \pm 2 \cdot 9$ & $3^{2 \cdot 2} \pm I \cdot 9$ \\
\hline 10.5 & $47 \cdot 6 \pm 2 \cdot 9$ & $3 I \cdot I \pm 2 \cdot 0$ \\
\hline I I 5 & $5^{2 \cdot 0} \pm 3 \cdot 2$ & $3^{2} \cdot 0 \pm 2 \cdot 4$ \\
\hline
\end{tabular}

\begin{tabular}{|c|c|c|}
\hline \multicolumn{3}{|c|}{ Series IV (I $\left.5^{\circ}+\mathrm{I}^{\circ} \mathrm{C}.\right)$. } \\
\hline Day. & Shoot. & Root. \\
\hline 4 & . $\quad .8 \mathrm{mg}$. & $9.8 \pm 0.39 \mathrm{mg}$. \\
\hline $4 \frac{1}{2}$ & $2 \cdot 2$ & $10.1 \pm 0.37$ \\
\hline & $3 \cdot 5$ & $10.7 \pm 0.40$ \\
\hline & $5 \cdot 2$ & $13.0 \pm 0.4^{2}$ \\
\hline $7 \frac{1}{2}$ & $7 \cdot 6 \pm 0.40$ & $16.4 \pm 0.55$ \\
\hline 9 & $I_{4} \cdot 2 \pm 0.39$ & $2 \mathrm{I} \cdot 3 \pm 0.57$ \\
\hline I I & $25.0 \pm 0.5^{2}$ & $26.2 \pm 0.72$ \\
\hline I 2 & $31.0 \pm 0.77$ & $27.6 \pm 0.7 \mathrm{I}$ \\
\hline 13 & $35.7 \pm 0.79$ & $26 . \mathrm{I} \pm 0.90$ \\
\hline I4 & $40.6 \pm 0.95$ & $26.6 \pm 0.83$ \\
\hline 16 & $46 \cdot 5 \pm I \cdot 10$ & $27.8 \pm 0.7 \mathrm{I}$ \\
\hline
\end{tabular}

Consideration of the rate curves for this series showed that prior to the appearance of secondary roots there seemed to be a negative correlation between the stem and root growth rates. When the stem rate increased that for the root decreased. After the appearance of secondary roots, stem and root growth both increased rapidly and roughly proportionately until the stem reached its maximum rate, when the root stopped growing, 
although the stem continued to grow at a decreasing rate. Since the stem still continued to grow rapidly it is clear that food supply from the cotyledons was not the factor preventing the further growth of the roots, and we must then suppose either that the stem entirely absorbed the cotyledonary food supply, preventing any material from reaching the roots, or else that some other factor preventing root growth was in operation. No evidence has been found for the latter assumption.

Possible objections to this series of observations were three in number.

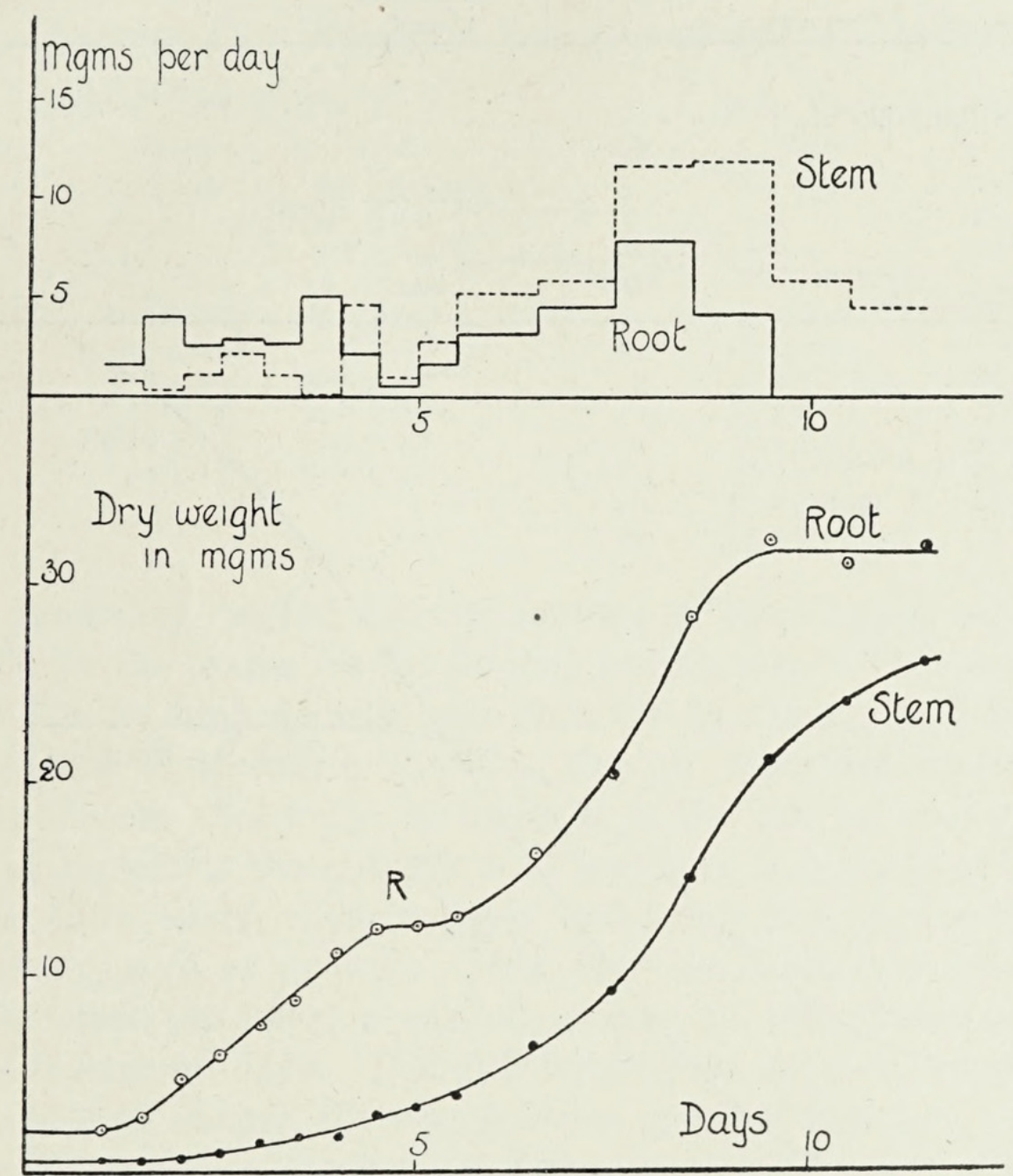

FIG. 2. Growth of stem and root (Series III) in peas at $25^{\circ} \mathrm{C}$. Secondary roots appeared at R. Stem curve reduced to half the vertical scale. (Rate curves above.)

(I) The variation of the plants and probable error of the determinations were so high that arguments based on the growth rate were barely justifiable. (2) The determinations were few in number after the appearance of secondary roots. (3) At the high temperature employed, the period of rapid growth was passed through so quickly that it was difficult to see whether or no any correlation existed between stem and root growth. Another series (IV) of determinations was therefore undertaken, the first objection above being met by the reduction of the variations as described in a previous paragraph (p. 263). The observations were carried out at lower temperatures 
$\left(\mathrm{I} 5^{\circ} \mathrm{C} . \pm \mathrm{I}^{\circ}\right)$, and the estimations were only begun after the appearance of secondary roots. The results obtained were similar to those of Series III (see Table II and Fig. 3), but in this case the stem had only completed about

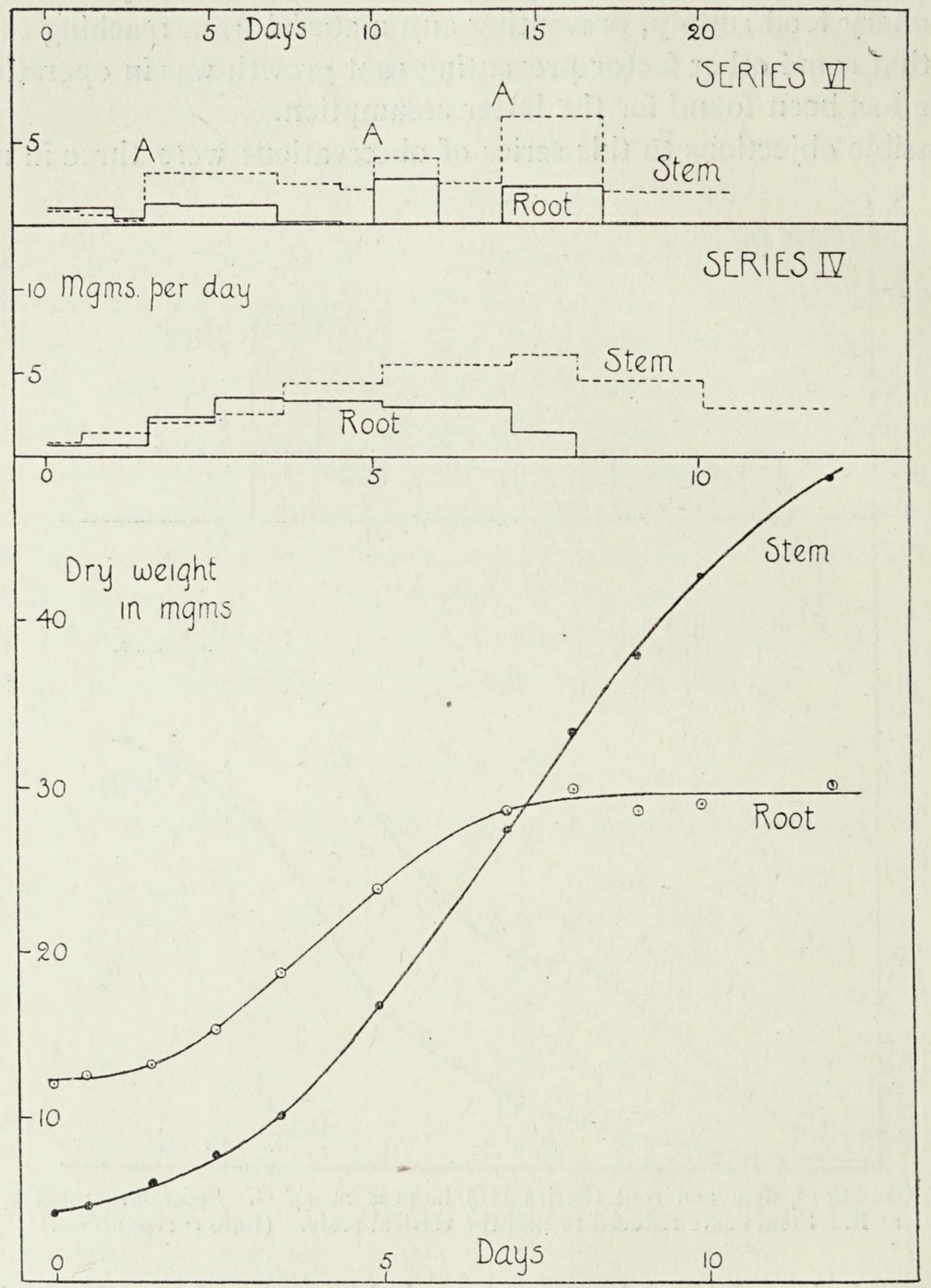

FIG. 3. Growth of stem and root in peas (Series IV) at $I 5^{\circ} \mathrm{C}$. after appearance of secondary roots. Rate curves of Series IV and VI are given above. In VI the nutrient solution was aerated at $\mathrm{A}$.

half its growth by the time the roots stopped growing. The rate curves seem to show a limiting of the rate of root growth when the stem growth rate becomes high. As the stem rate gradually increases, that for the root proportionately decreases, and this is quite definitely in harmony. with the view that the food supply is diverted to the stem apex-ultimately causing a stoppage of root growth. 
An additional series $(\mathrm{V})$, at the same temperature but using another variety of pea (round yellow) is given in Table III and Fig. 4. The results of this series are of the same type. Root growth after the appearance of secondary roots maintains a constant and apparently limited rate, while the stem rate is rising to a maximum. When the rate of stem growth shows a marked decrease root growth practically ceases.

\section{TABLE III.}

Average Dry Weight of Peas (round yellow variety).

\begin{tabular}{ccc}
\multicolumn{3}{c}{ Series $V\left(\mathrm{I}_{5} .0^{\circ} \pm \mathrm{I} .0^{\circ} \mathrm{C}.\right)$} \\
Day. & Shoot. & Root. \\
0 & $2.7 \mathrm{mg}$. & $8.6 \pm 0.2 \mathrm{mg}$. \\
I & $3 . \mathrm{I}$ & $9.1 \pm 0.3$ \\
2 & $4 . \mathrm{I}$ & $9.7 \pm 0.4$ \\
4 & $8.3 \pm 0.4$ & $14.3 \pm 0.4$ \\
7 & $25.2 \pm \mathrm{I} .0$ & $20.5 \pm 0.7$ \\
8 & $32.5 \pm 0.9$ & $21.7 \pm 0.6$ \\
I0 & $50.0 \pm \mathrm{I} \cdot 4$ & $26.2 \pm 0.8$ \\
I 2 & $64.3 \pm \mathrm{I} \cdot 7$ & $29.8 \pm 0.9$ \\
I5 & $78 . \mathrm{I} \pm 2 . \mathrm{I}$ & $32.0 \pm 0.8$ \\
I7 & $81.0 \pm 2.7$ & $31.9 \pm 0.8$
\end{tabular}

\begin{tabular}{|c|c|c|}
\hline \multicolumn{3}{|c|}{ Series $V I\left(\mathrm{I} 4 \cdot 8^{\circ} \pm \mathrm{I} \cdot 2^{\circ} \mathrm{C}.\right)$. } \\
\hline Day. & Shoot. & Root. \\
\hline 0 & $2.5 \mathrm{mg}$. & $\mathrm{I} 2.2 \pm 0.2 \mathrm{mg}$. \\
\hline I & $3 \cdot 4$ & $\mathrm{I}_{3} .2 \pm 0.4$ \\
\hline 2 & $4 \cdot 0$ & $14.3 \pm 0.3$ \\
\hline 3 & $4 \cdot 2$ & $14.7 \pm 0.4$ \\
\hline 4 & $7 \cdot 2 \pm 0.6$ & I6.1 \pm 0.6 \\
\hline 7 & $16 \cdot 3 \pm 1 \cdot 0$ & $20.0 \pm 0.6$ \\
\hline 9 & $2 \mathrm{I} \cdot 3 \pm \mathrm{I} \cdot 8$ & $20.1 \pm 0.5$ \\
\hline IO & $23 \cdot 5 \pm \mathrm{I} \cdot 2$ & $20.0 \pm 0.4$ \\
\hline I 2 & $31 \cdot 5 \pm I \cdot 2$ & $26.0 \pm 0.8$ \\
\hline$I_{4}$ & $36 \cdot 6 \pm \mathrm{I} \cdot 3$ & $25.8 \pm 0.8$ \\
\hline 17 & $5^{6.0 \pm I .45}$ & $32.4 \pm 0.9$ \\
\hline $2 \mathrm{I}$ & $63.2 \pm 1.6$ & $31.9 \pm 1.0$ \\
\hline
\end{tabular}

The possibility existed that the limiting of the oxygen supply to the roots mighit be the reason for the limited growth rate. This seemed to be disproved by the high growth rate obtained in the roots of Series III at a much higher temperature $\left(25^{\circ} \mathrm{C}\right.$.), though otherwise under precisely similar conditions. Secondly, no increase in the rate of root growth was obtained by replacing the nutrient solution more frequently or by aerating it. In the third place, when oxygen deficiency did appear it produced a distinct stoppage of growth. This may be illustrated by Series VI (Fig. 3), in which the solution was left unchanged, but aerated on the third, tenth, and fourteenth days. The dish holding the solution was in this case much smaller and deeper, the plants being crowded together. The lateral roots grew vigorously on the surface of the liquid, but, except after aeration, the main root and submerged laterals showed little or no growth. The effects of deficient oxygen supply were very marked in this case, and it is of interest to notice that the stoppage of root growth produced was associated with a marked reduction in the rate of stem growth-a feature not observable in the preceding series of observations. The facts clearly suggest, therefore, that the limitation of root growth rate in the earlier series was not due to deficient oxygen supply.

Further, since changing the nutrient solution more frequently produced no effect, and since there was no change in the results when the nutrient solution was reduced to one-fifth of the strength used in the series cited, it 
does not appear that the supply of nutrient salts was the limiting factor. The assumption that the stem was almost monopolizing the organic food supply, to the partial exclusion of the roots, seems best to fit the facts, and one would then expect the stem to go on growing after root growth had ceased, a significant feature of all the cases investigated.

The question can be considered from an entirely different standpoint.

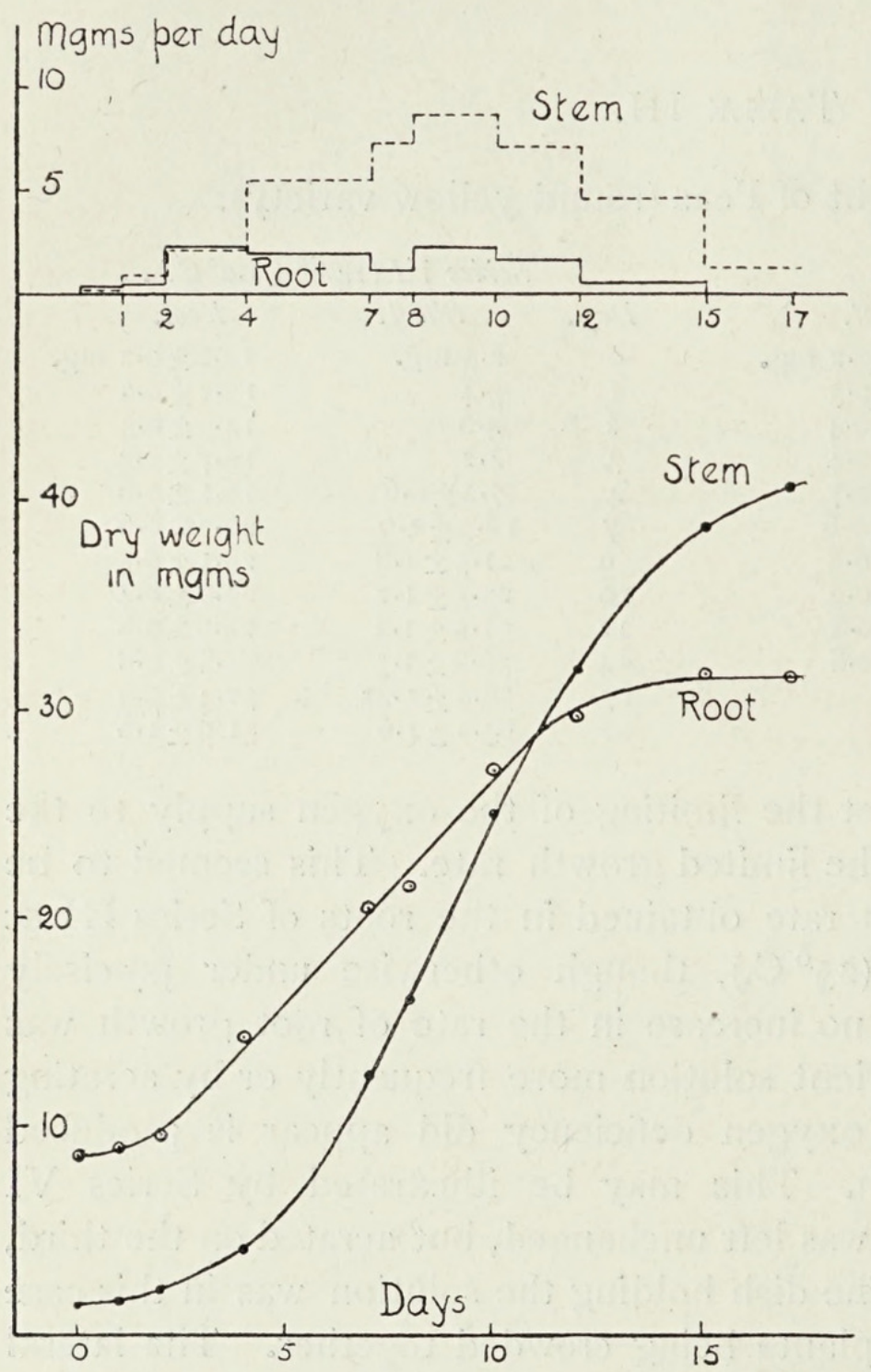

FIG. 4. Growth of stem and root (Series V) in peas after appearance of secondary roots. (Rate curves above.) Stem weight reduced by one-half.

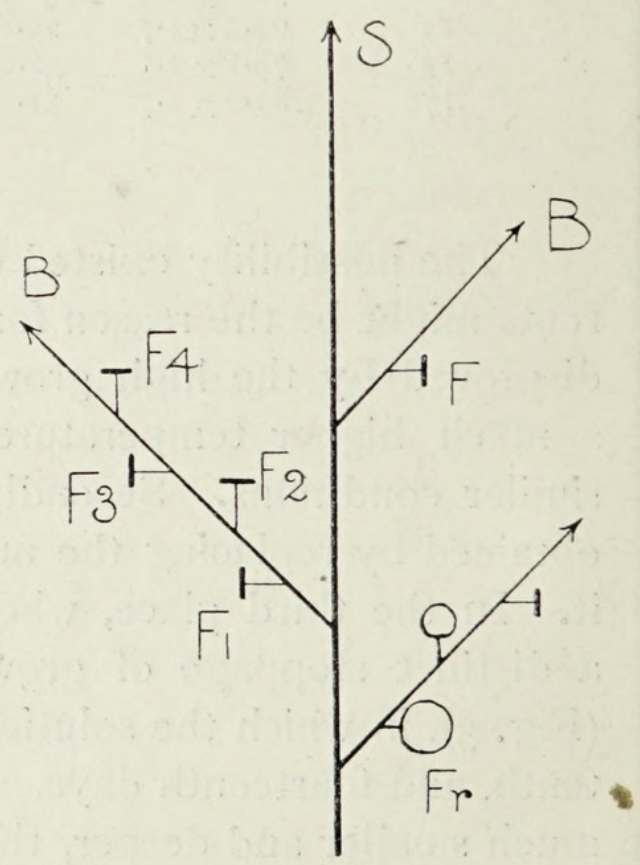

FIG. 5. For explanation see text.

After secondary root development, the total area of root meristem possessed by a plant is increased enormously and the rate of growth of the roots might therefore be expected to increase proportionately.

An examination of the rates of growth (by volume) before and after secondary root development in Series I (Nos. 2 and 3) shows that this is not the case, and a similar result is apparent when the following table is examined. This table shows the average growth rate of pea roots before and after secondary roots appear. 
TABLE IV.

Average Dry Weight Increase per Day of Pea Roots.

$\begin{array}{lcc} & \text { Before secondary roots. } & \text { After secondary roots. } \\ \text { Stem in light } \mathrm{I} 5{ }^{\circ} \mathrm{C} . & \mathrm{I} .6 \mathrm{mg} . & 2 \cdot \mathrm{I} \mathrm{mg} . \\ & \mathrm{I} \cdot 5 & \mathrm{I} \cdot 5 \\ & 1.6 & 2 \cdot 2 \\ \text { Stem in dark } \mathrm{I} 5{ }^{\circ} \mathrm{C} . & 2 \cdot 4 & 2 \cdot 9 \\ & \mathrm{I} \cdot 7 & \mathrm{I} \cdot 9 \\ & \mathrm{I} \cdot 6 & \mathrm{I} \cdot 5 \\ \text { Average } \mathrm{I} 5^{\circ} \mathrm{C} . & \mathrm{I} \cdot \mathrm{7} & 2 \cdot 0 \\ \text { Stem in dark } 25^{\circ} \mathrm{C} . & 3 \cdot 3 & 6 \cdot \mathrm{I}\end{array}$

These results do not include periods when root growth was seriously decreased. They are obtained by finding the average growth rate from curves such as are given in this paper. For example, the figures at $25^{\circ} \mathrm{C}$. are taken from Series III, the periods being $I \frac{1}{2}$ to 4 days and $6 \frac{1}{2}$ to $8 \frac{1}{2}$ days. The growth curves are practically straight lines between the points taken.

The only case in which a markedly increased average growth rate results after secondary root formation is at the higher temperature, and in this case we are probably justified in assuming that the rate of hydrolysis of food materials would be at least twice, probably about three times, as rapid, compared with that at a temperature of $15^{\circ} \mathrm{C}$. Preliminary estimations of the temperature coefficient of protein hydrolysis in bean cotyledons seem to support this assumption. Thus it appears probable that at a temperature of $\mathrm{I} 5^{\circ} \mathrm{C}$. food supply is the factor limiting root growth after the development of lateral roots. Since the forms of the curves for stem growth approximate fairly closely to those for the normal autocatalytic reactionwhich is now recognized as being a form of curve common in growth processes-it does not appear to be justifiable to assume any limitation of growth rate in the case of the stem, apart from that implied by a comparison between growth and an autocatalytic reaction. Hence the food supply to the root must be regarded as the residue remaining after the stem has withdrawn its supply.

The point of view developed above is in agreement with the earlier results of Kny (4) and Townsend (10). The papers of the former are somewhat unsatisfactory, but this author considered among other things the effect of removing the shoots from seedlings on the amount of root developed. This treatment, so far as any conclusion is possible from Kny's results, generally causes increased root growth in both Zea Mays and Vicia Faba, though in the latter case this effect is delayed. Townsend (10) also gives data for the effect of shoot removal on the rate of root growth in the same two plants. The roots of seedlings thus treated were 26 to 33 per cent. longer than those of normal plants five days after treatment. His results seem to be beyond suspicion, and justify the view that removal of the shoot allows an increased rate of food delivery to the root meristem. It 
may be pointed out in passing that the subsequent development of new shoots quickly reduces the rate of root growth to the original lower level.

The establishment of this negative correlation between shoot and root growth may apparently be extended much farther as a result of Townsend's work, although this author attributes his results to some stimulus caused by injury. He found that in seedlings the removal of the root tip accelerated the rate of stem growth, and that the removal of a leaf in a young Phaseolus resulted in an increased growth rate of the remaining leaf. The hypothesis that food supply is the factor limiting growth in these cases appears to be too suggestive to be lightly dismissed.

\section{CORRELATION IN THE COTTON-PLANT.}

Further, this hypothesis appears to have equal value in explaining the form of the flowering and fruiting curves in the cotton-plants. These curves have been exhaustively investigated by Balls and Holton $(1,2)$ and by Harland (3), and their papers form a valuable contribution to the study of growth. They conclude that edaphic factors limit the growth rate of the cotton-plants studied (in Egypt and St. Vincent), and according to Balls (2) the limiting factor is probably the supply of nitrates. With a limited rate of food supply the rapid growth of one set of organs should therefore mean a correspondingly decreased growth rate in other parts of the plant.

Thus in Fig. 5, where $\mathrm{S}=$ stem, $\mathrm{B}=$ branch, $\mathrm{F}=$ flower, and $\mathrm{Fr}=$ fruit, the sum of the growth of $S, B, F$, and Fr, will be a constant when the rate of food supply is constant. If, then, the growth of $S$ ceases, the growth rate of $\mathrm{B}, \mathrm{F}$, and $\mathrm{Fr}$ will increase proportionally; or conversely, if the growth rate of any organ, say $\mathrm{Fr}$, increases, the rate of growth of the others $(\mathrm{S}, \mathrm{B}$, and $\mathrm{F})$ should decrease.

If it is assumed that the supply of substance from the roots is a limiting factor in the total growth of the stem, \&c., then in the case figured the growth of the fruit (Fr) would proceed at its maximum speed, since it draws first on the supply stream, while some or all of the organs B, F, and $\mathrm{S}$ would grow at a reduced rate, the rate being least in those farthest from the source of supply X. Thus the rate of growth in the stem apex $(\mathrm{S})$ would, other things being equal, be the lowest in the case cited.

In Egyptian and Sea Island varieties of cotton, the development of stem apex, branches, flowers, and fruits occurs essentially as in the figure given. The exhaustive data of Balls and Holton $(1,2)$ and of Harland (3) are therefore available for a further analysis of these assumptions.

Their results are in all cases expressed as the average plant of a large crop, the number of plants being sufficient to eliminate most sources of error. They give the average number of flowers opening per plant per day, and the average number of bolls (fruits) maturing per plant per day. For 
one series of experiments Balls also gives the average length of the stem. This set of results has, therefore, been used, since it possesses the additional advantages of having been obtained in a long and favourable season (I9I3).

In the cotton-plant the flowers are borne successively on lateral branches. The oldest and longest branches at the base are the first to produce fruits, which appear while the upper branches are still producing flowers. Since the general arrangement of the plant is as in Fig. 5, the appearance of flowers ought to curtail the growth of the stem apex, and the development of fruits should reduce the rate of flowering, if the supply of

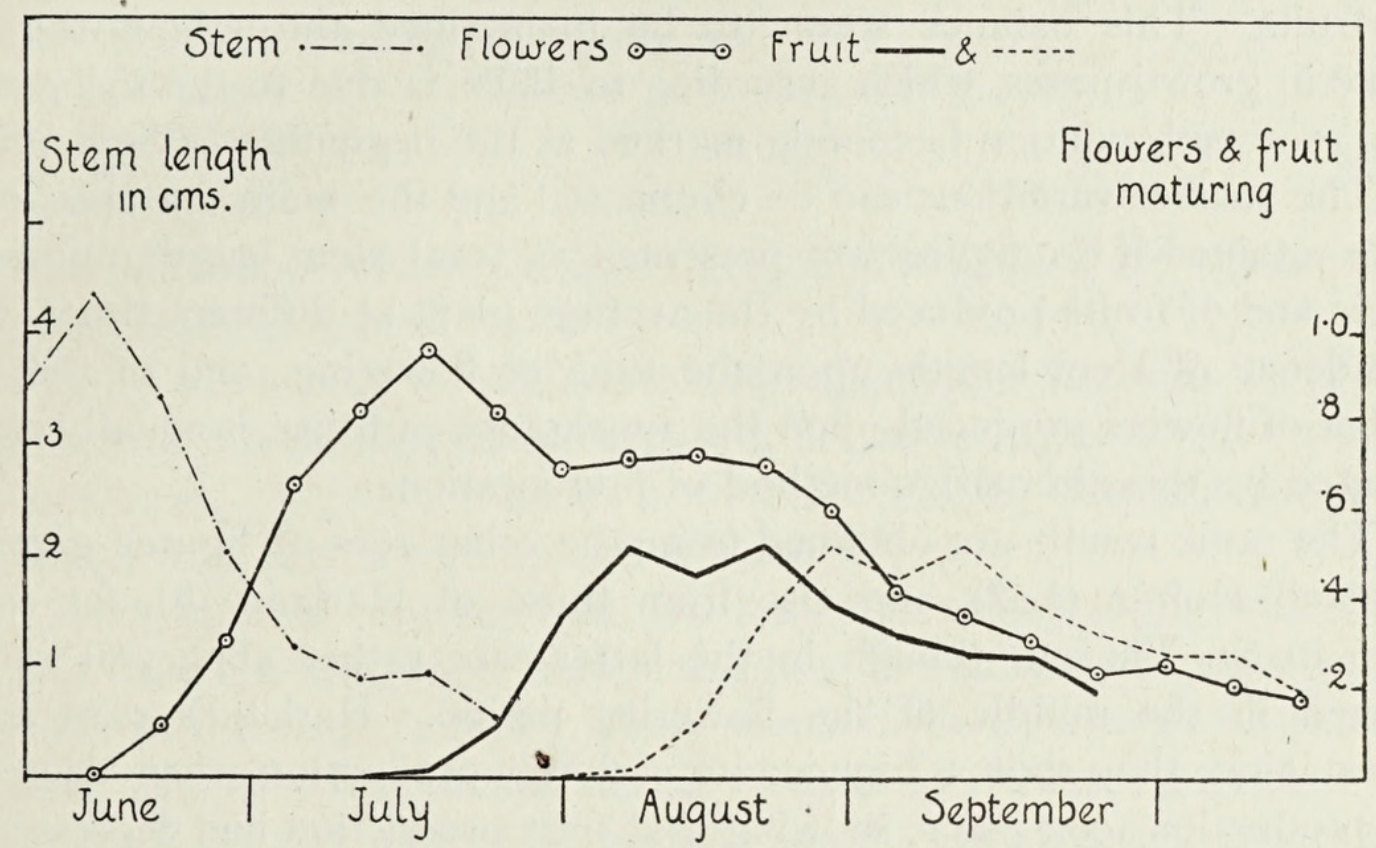

FIG. 6. Stem length, flowering and fruiting curves in Egyptian cotton (from the data of Balls and Holton), giving average increase per plant per day. The continuous fruiting curve is put forward three weeks (see text).

food material from the roots is the limiting factor in the total growth rate of the plant.

The results of Balls and Holton $(1,2)$ for the Middle Period sowings in the sowing date experiments of I9I 3 appear to justify this assumption. They are given as weekly averages (Fig. 6), for increase in stem length, flowers opening, and fruits maturing per plant per day. It is apparent that the decreased rate of growth of the stem after June I 3 coincides with the development of flowers nearer the base of the plants. After July 18 the flowering rate also decreases, and this is followed by the development of the fruits. The flowering and fruiting curves do not actually represent the effects of the developing fruits on the flowering curves. The flowers give rise to mature fruits about seven weeks later (Balls, loc. cit.), but the fruits grow most rapidly about two (or two and a half) weeks after flowering. Since the flowers take four weeks to develop, we can assume they are growing most rapidly about a fortnight before they open. Hence the most 
rapid growth of the fruits takes place four (or four and a half) weeks after the most rapid growth of the flowers. Thus, roughly, the food demands of the fruits will follow those of the flowers by about four (or four and a half) weeks; instead of by seven weeks, and to represent the effect of fruit development upon the flowering curve, from this point of view, the fruiting curve needs to be transposed three (or two and a half) weeks earlier (i.e. seven to four). The drop in the flowering rate then appears to be directly related to the increase in the numbers of fruits, and the horizontal portions of the curves also coincide, representing a condition of equilibrium when constant proportions of the food supply are used respectively by flowers and fruits. This balance seems to be maintained throughout the final decline in growth rates, which according to Balls is due to the rising water table, root asphyxiation becoming marked at the beginning of September.

The smaller variations can be eliminated and the main features of the curves retained if the figures are presented as total stem length, number of flowers and of fruits produced by the average plant at different times. The dependence of stem length upon the time of flowering, and of the total number of flowers produced upon the appearance of fruits, is equally clearly indicated by this alternative method of presentation.

The same results are obtained from the other sets of figures given by Balls and Holton $(1,2)$, and also from those of Harland (3), for cotton grown in St. Vincent, though in the latter case rather abnormal rainfall occurred in the middle of the flowering period. Harland's data are of interest, since they show a higher rate of flower production when decreased fruit production took place, showing that fruit production had depressed the rate of flowering.

We may pass on to consider other aspects of the development of cottonplants which seem to fall in line with the views put forward here. The valuable data of Harland (3) are of particular interest in this respect, since he analyses statistically the growth of various parts of the plants, though attempting no explanation of his results.

Referring to Fig. 5, on any branch $\mathrm{B}$ the order of flowering is $\mathrm{F}_{1}, \mathrm{~F}_{2}$, $\mathrm{F}_{3}$, \&c. If the growth rate of the branch is uniform then time intervals, $\mathrm{F}_{1}$ $\mathrm{F}_{2}, \mathrm{~F}_{2}-\mathrm{F}_{3}, \mathrm{~F}_{3}-\mathrm{F}_{4}$, \&c., should be uniform. Harland shows statistically that actually in cotton the time interval between the flowering of adjacent nodes $\left(\mathrm{F}_{1}-\mathrm{F}_{2}, \mathrm{~F}_{2}-\mathrm{F}_{3}\right.$, \&c. $)$ increases as the distances from the central branch increase. Hence a point is reached when the rate of growth is practically zero. When it is remembered that each flower may produce a fruit, i.e. a growing-point nearer the source of supply (the stem), it seems possible to explain the falling off in growth rate of later nodes as being due to the growth of fruits lower down the branch, which serve to reduce the rate of food supply to the branch apex.

Harland also shows that, in a precisely similar way, the time interval 
between the first and second flowers on a branch increases as the distance of the branch from the lowest fruiting branch increases.

$\begin{array}{lccc}\text { e.g. fruiting branches } & 20-30 & 30-40 \\ \text { Average time interval be- } & \text { I-20 } & 6 \cdot 2 & 7 \cdot 9 \\ \text { tween first and second } & & 5 \cdot 1 & \end{array}$

It seems clear that growth on the lowest branches proceeds at a maximum rate, because these branches draw first on the food supplies from the roots, the higher branches only receiving the residue.

In addition, the first node on each branch flowers later than the first node on the branch below it, and these time intervals increase as one ascends the stem. Harland's figures are:

$\begin{array}{ccccc}\begin{array}{c}\text { Fruiting branches } \\ \text { Time interval between } \\ \text { first nodes on succes- } \\ \text { sive branches (days) }\end{array} & 1-20 & 20-25 & 25-30 & 30-40 \\ \text { Tive } & 2 \cdot 2 & 3 \cdot 5 & 3 \cdot 7 & 4 \cdot 6\end{array}$

The individual variation is much greater, the greater the distance from the lowest fruiting branch.

Finally the number of nodes per fruiting branch decreases from below upwards, and the average percentage of fruits maturing to flowers produced decreases from $33-37 \cdot 8$ for nodes I to 3 on fruiting branches to $14 \cdot 9-10$ for nodes 4 to 6 , and is zero on nodes 7 and 8 .

The abortion of terminal buds on branches occurs along with flowerbud and fruit shedding, and may, according to Harland, be considered as being due to the same factors. There seems to be no reason why this and the other facts described should not be referred to decreasing growth rates, consequent upon the limiting of the food supply. In all the cases considered for cotton there are developing growing-points nearer the roots than are the later fruits and flowers or the branch apices. In the case of roots growing from seeds, the growth of the stem limits the food supply to the roots and hence, reduces their growth rate. The diminution of growth rate observable in cotton as the growing organs get farther from the base of the stem seems to show an exactly comparable state of affairs.

The effect of manurial treatment has been shown by both Balls $(1,2)$ and Harland (3) to leave the form of the flowering and fruiting curves unaltered, but to increase the rate of flowering and fruiting throughout. If more of the limiting nutrient substances are available and are passing up the stem, then more will pass the lower growing-points, and the rate of growth of the later flowers and fruits will increase, so that the rate of flowering and fruiting as a whole will be increased. Thus the manurial results agree with the hypothesis developed here.

\section{Additional Note.}

Since writing these paragraphs a valuable statistical analysis of correlation in the cotton-plant has appeared (Mason, 5), which fully confirms the 
views put forward above. The author shows, in brief, that removal of the flowers or developing fruit permits a further development of stem elongation. He suggests, however, that this is due to the downward movement of carbohydrates to the fruits. This involves the assumption of a correlating factor which causes the deflexion of assimilates from the apical region to the developing fruit. Two sets of facts demonstrated by Mason seem to be opposed to these assumptions. In the first place, the removal of vegetative branches causes only a slightly increased rate of axis elongation, while flower formation is increased by 50 per cent. Secondly, the correlation coefficients between neighbouring fruiting branches are greatest in the apical region. Both of these facts can, however, be readily explained on the assumption used in the preceding pages, that food supply from the roots is the limiting factor. In the latter case, the flowers would draw first on this supply and the removal of the vegetative branches would thus increase food supply to the flowers, allowing only the excess materials to reach the stem apex. Moreover, the farther the fruiting branches are away from the source of supply the more rigidly would their activity be limited by the food supply and the closer would be the correlation between successive branches.

\section{SumMary.}

I. Data are presented for the growth of roots from seeds, measured as changes of volume and of weight.

2. The evidence shows that the development of subordinate roots upon roots of seedlings causes a temporary decrease in growth rate. The increase in the size of the root meristems after secondary root production appears to produce no corresponding increase in the growth rate of the whole root. The stem continues to grow after the root has stopped.

3. The observed facts are consistent with the hypothesis previously developed that food supply is a limiting factor in the early periods of root growth from seeds and cuttings. The stem is assumed to compete successfully with the root for the cotyledonary food supply, especially after the development of secondary roots, thus causing a reduction of the root growth rate.

4. The data of Balls and of Harland for growth of stem, flowers, and fruits in cotton are examined, as representing a case in which food supply from the roots is assumed to be a limiting factor.

5. It is shown from these results that in cotton the decreased rate of growth of the stem can be attributed to flowering, and that subsequently the decreased flowering rate can be attributed to the development of fruits nearer the source of supply of the presumed limiting food factors. 


\section{LITERATURE CITED.}

1. Balls, W. L., and Holton, F. S. : Analyses of Agricultural Vield, I and II. Phil. Trans. Roy. Soc., B., ccvi, I9I5.

2. BALls, W. L. : Analyses of Agricultural Yield, III. Ibid., ccviii, I9I8.

3. Harland, S. C. : Manurial Experiments with Sea Island Cotton in St. Vincent, \&c. West Indian Bull., xvi. 3 , I91 7 .

4. KNy, L.: On the Correlation in the Growth of Roots and Shoots. Ann. Bot., viii. 265, 1894 , and xv. 613, I90I.

5. Mason, T. G. : Growth and Correlation in Sea Island Cotton. West Indian Bull., xix. 2, 1922.

6. Priestley, J. H., and Evershed, A. F. C. H.: Growth Studies. I. A Quantitative Study of the Growth of Roots. Ann. Bot., xxxvi. 225, 1922.

7. and Pearsall, W. H.: II. An Interpretation of some Growth Curves. Ibid., p. 239, 1922 .

8. III. A Volumometer Method of Measuring the Growth of Roots. Ibid., p. 485,1922 .

9. Shive, J. W.: A Study of Physiological Balance in Nutrient Media. Physiol. Researches, i, 1916.

10. Townsend, C. O.: 'l'he Correlation of Growth under the Influence of Injuries. Ann. Bot., xi. 509, 1897. 


\section{$2 \mathrm{BHL}$ Biodiversity Heritage Library}

Pearsall, W. H. 1923. "Studies in growth. IV. Correlations in development." Annals of botany 37, 261-275.

https://doi.org/10.1093/oxfordjournals.aob.a089845.

View This Item Online: https://www.biodiversitylibrary.org/item/270686

DOI: https://doi.org/10.1093/oxfordjournals.aob.a089845

Permalink: https://www.biodiversitylibrary.org/partpdf/319082

\section{Holding Institution}

New York Botanical Garden, LuEsther T. Mertz Library

\section{Sponsored by}

BHL-SIL-FEDLINK

\section{Copyright \& Reuse}

Copyright Status: Public domain. The BHL considers that this work is no longer under copyright protection.

This document was created from content at the Biodiversity Heritage Library, the world's largest open access digital library for biodiversity literature and archives. Visit BHL at https://www.biodiversitylibrary.org. 